\title{
ALGUNAS CONSIDERACIONES SOBRE LA DEÍXIS EN ESPAÑOL Y EN ÁRABE
}

\author{
Waleed SALEH ALKHALIFA
}

Escuela Oficial de Idiomas de Valencia

El objetivo de este breve trabajo es fundamentalmente aproximarse a la deŕxis en lengua árabe, partiendo de algunos estudios realizados sobre todo en lengua española y sobre la misma.

Lamentablemente no encontramos suficientes estudios lingüísticos modernos sobre la lengua árabe. Nos referimos a aquellos estudios que tengan en cuenta las teorías y los avances lingüísticos en otras lenguas, sobre todo europeas.

La mayor parte de los trabajos e investigaciones que manejan los estudiantes y profesores de la lengua árabe son de carácter tradicional, escritos especialmente por autores medievales. Con esto no queremos decir que exista una ausencia total de estudios linguísticos modernos, porque serfa injusto ignorar el trabajo de decenas de estudiantes que han realizado sus tesis doctorales y otros que lo siguen haciendo en muchas capitales europeas y americanas. Pero lo cierto es que esas investigaciones, en su mayoría, quedan rehenes de los departamentos y facultades donde son presentadas, y no ven la luz casi nunca con su publicación.

Por todo esto el lector árabe se queda al margen de las nuevas teorías lingüísticas que podrían serle muy útiles, y en el mejor caso le llegan traducidas al árabe con un retraso considerable, como ha sido el caso del Estructuralismo, la Escuela Generativa y los estudios de Chomsky. 


\section{La Deíxis}

Antes de entrar en materia, queremos saber qué significa ese término. La derxis (procede de una palabra griega que significa "señalar" o "indicar") se puede definir como la localización y la identificación de las personas, objetos, procesos, acontecimientos y actividades de que se habla por relación al contexto espacio-temporal creado y mantenido por el acto de enunciación (Lyons: 1980, 261).

Según Jakobson, no sólo los defcticos remiten a la enunciación, sino también el tiempo y el modo del verbo (Lozano: 1989, 97). En esto se puede destacar la dualidad de la teoría de Jakobson que articula el "proceso y protagonistas de la enunciación" con el "proceso y protagonistas del enunciado".

La teoría de la enunciación se ocupa de describir las trazas del acto de enunciación en su producto, el enunciado. Por "enunciación" se entiende el acto individual de utilización de la lengua; la teoría de la enunciación intenta estudiar la enunciación dentro del enunciado, su producto, incorporando así en el análisis lingüístico el problema del sujeto y su manifestación en el discurso (Reyes: 1990, 134).

De esto se entiende que el hablante se apodera del aparato formal de la lengua y enuncia su posición de locutor por medio de indicios especificos. Así que el hablante se confirma al emitir su enunciación como identidad "yo". También se confirma el tiempo "ahora" y el espacio "aqui".

La presencia de los dos factores del acto de habla, es decir, E y R es fundamental en la déxis o mostración, pues no tendría sentido si no se mostrara algo o alguien. El que muestra, en el acto comunicativo, es evidentemente el Emisor. Por eso en la deíxis hay un desglosamiento (E-R) y una transitivización del contexto natural (Calvo: 1989, 149).

Sabemos que todas las lenguas tienen algunas formas especiales para codificar diferentes tipos de elementos de la situación comunicativa que se conocen como los décticos. Escandell nos pone un ejemplo aclaratorio que explica este punto con precisión, y que dice: Imaginemos que encontramos un papel en el suelo con el texto siguiente: "Te espero mañana donde siempre" (Escandell: 1993, 25). La autora añade que el hablante nativo de la lengua española conoce todas las palabras del texto y comprende el significado sin ninguna dificultad. Pero este 
mensaje, estando fuera de cualquier contexto, es difícil saber a qué se refiere con exactitud, porque faltan algunas informaciones sobre el sujeto del mensaje, el destinatario, el tiempo exacto al cual se refiere la palabra "mañana" y cuál es el lugar "donde siempre".

Podemos añadir muchos ejemplos de este tipo que no se pueden entender de forma completa por estar fuera de su contexto, como:

- Nos veremos en el café dentro de dos horas.

- Esta noche os espero en el mismo restaurante.

En estas dos frases también el emisor, el receptor, el lugar y el tiempo son bastante ambiguos, porque, como ya hemos dicho antes, todo queda fuera de su contexto natural.

Así vemos que una gran parte de la interpretación de los enunciados depende fundamentalmente de factores extralingüísticos, que son la identidad del emisor, receptor, lugar y tiempo de dicho enunciado, para comprender su mensaje de forma plena. Precisamente la pragmática es la que se ocupa de estudiar estos casos con el fin de tener acceso a todo tipo de información precisa.

Los deícticos comprenden los pronombres personales, los demostrativos, los posesivos, los adverbios de lugar y de tiempo, y también los morfemas de tiempo de la flexión verbal y las fórmulas de tratamiento. Habría que añadir además de todo esto, las formas anaforicas y catafóricas que se usan en el discurso para hacer referencia a algunas partes del propio discurso.

A continuación hablaremos de la deíxis en lengua árabe, deteniéndonos en los casos especiales y peculiares de esta lengua que, como todas las lenguas del mundo, tiene cosas comunes con las demás y aspectos particulares que no existen más que en ellas.

\section{a) Deíxis de persona}

La deíxis de persona señala al sujeto de la enunciación, Emisor "yo" $o$ al que va dirigido la enunciación, Receptor "tú". También puede señalar a un elemento necesario como referencia absoluta que es "él".

Los pronombres personales en árabe son: 
$1^{\text {a }}$ Persona

Sing.

أن (anā) "yo"

Dual

Pl.

$$
\begin{aligned}
& \text { (nahnu) "nosotros (-as) dos" } \\
& \text { نَحْنْ (nahnu) "nosotros (-as)" }
\end{aligned}
$$

2a Persona

Sing. m. أنتَ (anta) "tú"

Sing. $f$.

Dual m. y f.

$$
\text { أن أنتـ (anti) "tú" }
$$

Pl. m.

Pl. f.

$$
\text { أنتُشَ' (antumā) "vosotros (-as) dos" }
$$

$$
\text { (antum) "vosotros" }
$$

$3^{a}$ Persona

Sing. $m$.

Sing. $f$.

$$
\text { هـو (huwa) "él" }
$$

Dual m. y f.

PI. m.

Pl. f. (hiya) "ella"

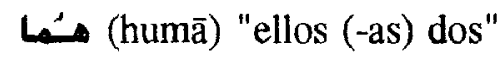$$
\text { هـ (hum) "ellos" }
$$$$
\text { هُ (hunna) "ellas" (Abū Sa‘ad: 1987, 36) }
$$

Los manuales y los libros de gramática árabes clasitican las personas como (mutakallim) hablante, (mujātab) persona a quien se dirige el hablante o el interpelado y (gā'ib) ausente, sucesivamente.

$/ \mathrm{Yo} / \mathrm{y} / \mathrm{tú} /$ remiten a los actores en el drama verbal actual, a los actores de la acción verbal (Bühler: 1979, 131).

El /yo/ es la persona que enuncia, es el sujeto de la enunciación. Forma con /tú/ una correlación de subjetividad. Se puede definir como la persona "no-yo", o la persona no subjetiva.

El /yo/ y /tú/ es idéntico al español, aunque tenemos en árabe un $/$ tú/ masculino (anta) y otro femenino (anti). Como anécdota podemos mencionar un dicho árabe relacionado con el /yo/; cuando alguien habla de sí mismo dice: "Yo, y Dios me libre de la palabra "yo" soy una 
persona ...». El hablante en este caso no quiere darse ningún tipo de protagonismo o importancia, es una muestra de humildad.

Lo peculiar en el árabe es el uso del dual de primera, segunda y tercera persona. Pero cabe señalar que el uso del dual es bastante reducido, ya que éste en dialecto es sustituido por el plural.

En primera persona coincide con el plural (nahnu) nosotros/-as o nosotros/-as dos. En cambio, la segunda y la tercera persona tienen su pronombre personal propio

Tú (anta/anti) + tú (anta/anti) = Vosotros (-as) dos (antumā).

Tú (anta/anti) + él/ella (huwa/hiya) $=$ Vosotros (-as) dos (antumā).

Él/ella (huwa/hiya) + él/ella (huwa/hiya) $=$ Ellos/ellas dos (humā).

Queremos hacer un inciso en cuanto a la existencia del dual en la lengua árabe. La evolución del árabe se detiene, como sabemos, con la aparición del Islam en el siglo VII, cuando el árabe alcanza su plena formación con el Corán. Este libro marca para siempre el habla de los árabes y se convierte en la lengua estándar para ellos.

Los elementos básicos del árabe se encuentran sobre todo en la poesía y la prosa preislámicas. En dicha poesía y prosa el uso del dual era frecuente y lo podemos comprobar en los poemas que nos han llegado a través del tiempo.

Los filólogos y estudiosos coinciden en señalar el motivo del surgimiento del dual subrayando algunos puntos concretos que podemos resumir en lo siguiente:

La figura de dos personas tenía una presencia importante en la sociedad árabe preislámica de aquel entonces e incluso de la islámica posteriormente durante varios siglos. El señor y su criado, el marido y la mujer, el beduino y su compañero que no siempre era de la especie humana, puesto que podía ser algún animal: caballo, camello ... y como éstos eran muy considerados en la vida de aquella gente, en muchas ocasiones les daban trato de personas. Al encontrarse unos con otros, el hablante necesitaba en su caso esta figura del dual para dirigirse a sus interlocutores.

Uno de los poemas más antiguos que han llegado hasta nosotros en lengua árabe es el del rey poeta Umru' al-Qays de principios del siglo VI en cuyo primer verso encontramos un verbo imperativo dirigido al dual que dice: 


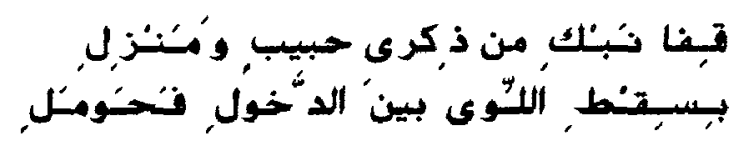

"Parad (vosotros dos) para llorad el recuerdo del amado y su morada ..."

Como ya hemos señalado, la mayoría de los críticos coinciden con explicar este imperativo junto a otros muchos usos del dual de esa poesfa, diciendo que el poeta dirigra sus palabras a su criado y a su caballo.

No falta quien justifica el uso del dual dirigido al singular por cortesía y respeto, o como dicen otros que la compañía mínima es de dos por lo cual la necesidad del dual era muy amplia y así lo utilizaban para una, dos o más personas de forma general.

Dice un poeta anónimo:

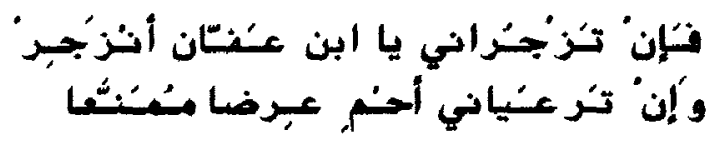

"¡Oh, Ibn 'Affān! si me reprocháis (vosotros dos) acataré vuestro reproche ..." (Al-Zawzanī: s.d. 7).

En este verso el poeta se dirige a una persona, pero utiliza el verbo en dual.

\section{Usted}

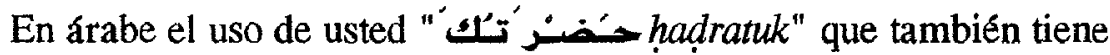
sus formas en masculino, femenino y singular, dual y plural, es bastante reducido, porque el trato más corriente es la forma tú.

Se utiliza usted "hadratuk" al dirigirse a las personas mayores o de rango social, directivo, administrativo...

Pero a diferencia del castellano la forma del verbo se hace en árabe en segunda persona y no en tercera como el español. Si en castellano decimos: usted va por esta calle ..., en árabe sería: usted vas por esta calle... También decimos: ustedes vais por aquí...

Es más conocido y usual la utilización de vosotros (أنتَم "antum" con su forma verbal correspondiente para tratar a una persona mayor como una fórmula de cortesía y de respeto. Esta forma es también 
habitual en los escritos administrativos, en las instancias y en los demás documentos oficiales a la hora de dirigirse a algún ministro, director, presidente...

En esta misma línea se puede señalar el saludo árabe islámico (الستّلام عـليكُم ("al-salām "alaykum" ("que la paz sea con vosotros"). Este saludo, como vemos, dirigido al plural masculino, no cambia si es dirigido a una o dos personas, tampoco si es (son) hombre (-s) o mujer (-es).

\section{Ella-ellas}

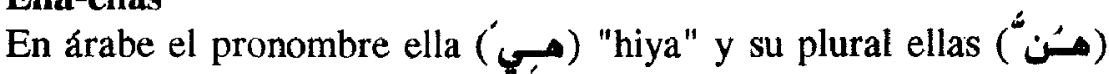
"hunna", se caracteriza en líneas generales por los mismos usos en lengua española. Pero lo cierto es que existe una peculiaridad que merece ser señalada por formar un aspecto particular del árabe y creemos difícil encontrar algo parecido a eso en otras lenguas. Nos referimos al uso de ella, pronombre personal de $3^{a}$ persona del femenino singular que se utiliza obligatoriamente al indicar cualquier plural irracional, masculino o femenino, por ejemplo:

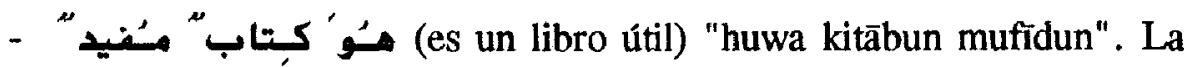
traducción literal serfa: él (es) un libro útil.

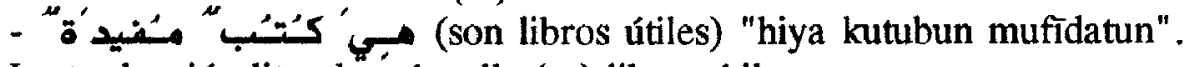
La traducción literal sería: ella (es) libros útiles.

La palabra libro en árabe es masculina, pero sería lo mismo si utilizáramos un plural de femenino irracional, por ejemplo:

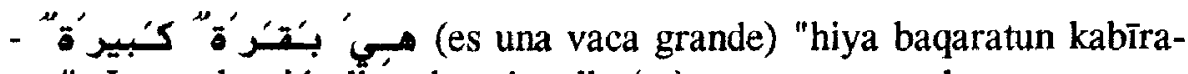
tun". La traducción literal sería: ella (es) una vaca grande.

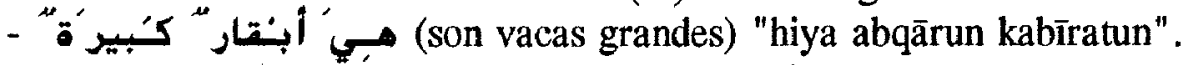
Su traducción literal sería: ella (es) vacas grandes.

Este trato se repite con el demostrativo, el relativo, el adjetivo y el verbo. Por ejemplo:

(estas gallinas son blancas) "hādihi 1daŷāŷātu bayḍā'u". La tráducción literal es: esta gallinas es blanca. 


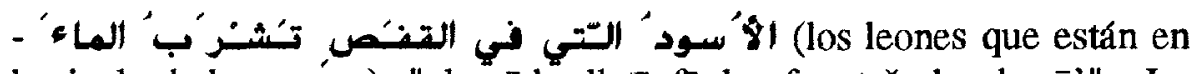
la jaula beben agua) "al-usūd allatī fi l-qafaș tašrab al-mā'". La traducción literal es: los leones, la que está en la jaula bebe (ella) agua.

\section{b) Deíxis espacial}

Los demostrativos en árabe llamados أستُما ' الاششار (los nombres demostrativos) sirven para hacer referencia a la distancia a que se encuentran otros. En árabe, dicha referencia admite tres grados: próximo, medio y lejano o remoto. En la práctica se utilizan los indicadores de la distancia próxima y lejana. Sus formas están contenidas en el siguiente cuadro:

\begin{tabular}{|c|c|c|c|c|}
\hline & gen. & singular & dual & plural \\
\hline $\begin{array}{l}\text { deíxis } \\
\text { próxima }\end{array}$ & $\begin{array}{l}\text { mas. } \\
\text { fem. }\end{array}$ & $\begin{array}{l}\text { شـ/hādä } \\
\text { Aـذ/hādihi }\end{array}$ & 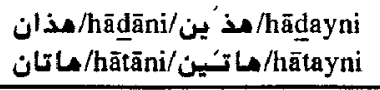 & 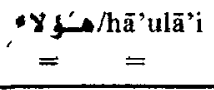 \\
\hline $\begin{array}{l}\text { deíxis } \\
\text { media }\end{array}$ & $\begin{array}{l}\text { mas. } \\
\text { fem. }\end{array}$ & 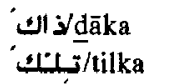 & 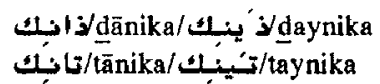 & 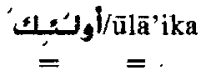 \\
\hline $\begin{array}{l}\text { deíxis } \\
\text { alejada }\end{array}$ & $\begin{array}{l}\text { mas. } \\
\text { fem. }\end{array}$ & 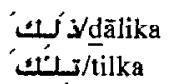 & 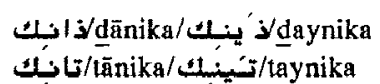 & 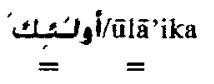 \\
\hline
\end{tabular}

(Ver Riloba: 1986, 79-80; Corriente: 1984, 111 y Abu Sa'ad: 1987, 41)

\section{Observaciones}

1.- Los demostrativos de la deŕxis próxima se pueden utilizar sin

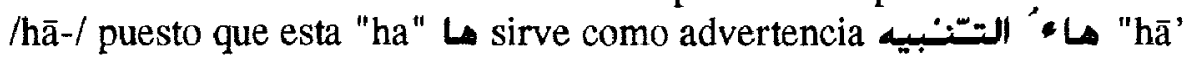
al-tanbih".

2.- Todos los nombres demostrativos excepto los del dual son indeclinables o invariables. En cambio el dual tiene dos formas: una para el nominativo y otra para el genitivo y acusativo.

3.- El plural tiene una forma única para el masculino y el femenino tanto para la deíxis próxima como para la media y alejada.

4.- Los demostrativos del plural se emplean sólo para los seres racionales, y se emplea para los seres irracionales el demostrativo del singular femenino como ya se ha dicho anteriormente.

Demostrativos de lugar: el lugar, según J. Calvo, es el más importante de los tres desde el momento en que con él se acota el 
subconjunto arcal primario que envuelve tridimensionalmente al hablante (Calvo: trabajo inédito sobre la déxis, 55).

Los nombres demostrativos que hacen referencia al lugar en árabe

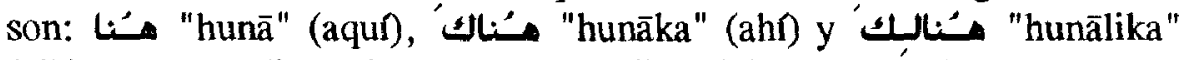
(alli), para las distancias cercana, media y lejana respectivamente.

Puede ser interesante hablar del uso peculiar de los demostrativos de la distancia media y lejana cuando pierden su indicación deŕctica, expresando el significado del verbo existir o haber, por ejemplo:

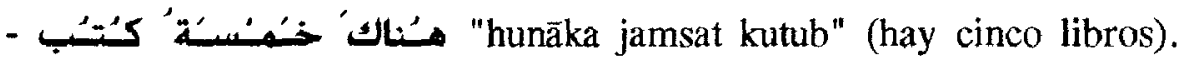
Literalmente la frase dice: "ahi cinco libros".

- مسنالِك " hunālika al-katīr min al-mašākil" (Exísten muchos problemas). Literalmente la frase dice: "allí muchos problemas".

En cambio هـ (aqui) no tiene este uso y se emplea únicamente para indicar el lugar: deíxis mostrativa "ad oculus" o anafórica como veremos más adelante.

Existe otro nombre demostrativo que indica lugar lejano como

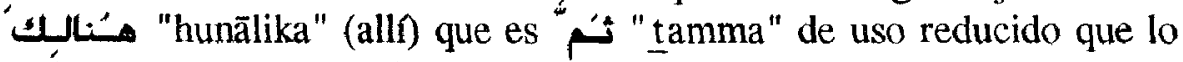
podemos encontrar fundamentalmente en los textos literarios.

Pero el dialecto marroquí toma este demostrativo y lo emplea con una pequeña deformación, pronunciándolo " $ّ$ "timma", es decir, convirtiendo la letra

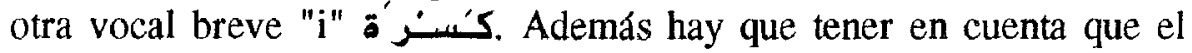
dialecto marroquí no pronuncia nunca la letra $\omega$ " $\underline{t}$ " sino que la hace siempre $ت " t "$.

Este demostrativo se emplea a su vez con el significado de existir o haber.

\section{c) Deíxis de tiempo}

Los deícticos temporales en árabe codifican como en español el espacio de tiempo de sol a sol, aunque como veremos más adelante, la división del día no coincide de forma total con la española.

Hay que hacer una distinción entre los adverbios en árabe y otras lenguas, ya que éstos llevan en lengua árabe muy clara la indicación espacial o temporal y sólo pueden indicar lugar o tiempo, por lo tanto 
no se consideraban adverbios palabras como pues, más, poco, bien, también ... sino que se le da otra categoría gramatical.

El día se divide en dos grandes partes: شُش "nahār" (jornada diurna o todo el tiempo en el que existe la luz natural o del día) y لَيُل "layl" (noche o el perfodo nocturno que es el tiempo en el que falta la luz del día).

Existen palabras concretas que indican partes del día o de la noche que se emplean como adverbios (el caso del adverbio es el acusativo). En cambio estos términos hay que expresarlos con una frase o varias palabras.

Por ejemplo:

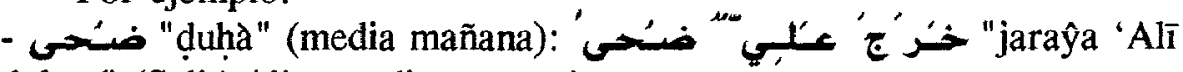
ḍuhan" (Salió Ali a media mañana)

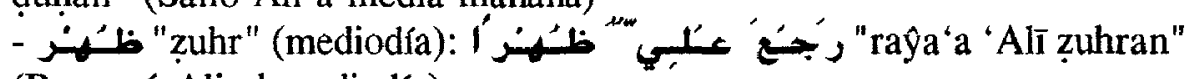
(Regresó Ali al mediodía)

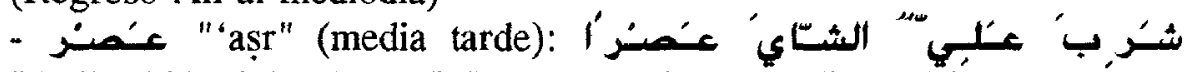
"Šariba "Alī al-šày "așran" (Tomó Ali el tế a media tarde)

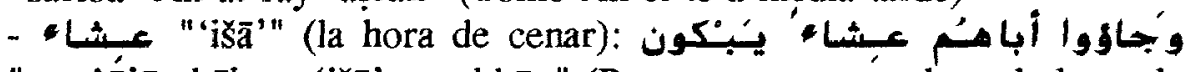
"wa-ŷầ' ā abāhum 'išā'an yabkūn" (Regresaron a su padre a la hora de cenar llorando) (al-Qur'än: 12,15).

Todos estos adverbios pueden utilizarse como sustantivos en otros contextos para emplear el papel de sujeto, complemento directo...

Los demás adverbios son parecidos a los que existen en español, aunque algunos de ellos se expresan de manera distinta, como:

- بـعـد "ba“da sā'a" (dentro de una hora), literalmente es: después de una hora.

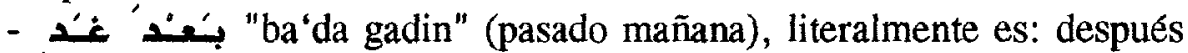
dé mañana.

La preposición (por) utilizada tanto en español para indicar el tiempo: por la mañana, por la tarde... no es necesaria en árabe y se puede eliminar como: غُدا ليلا ليلا "gadan laylan" (mañana por la noche). Literalmente dice: mañana noche.

En cuanto al tiempo del verbo en árabe, podemos afirmar que también existen los tres: pasado, presente y futuro, como en otras lenguas. Pero lo peculiar de esta lengua es que en algunos casos se 
utiliza el presente para indicar el pasado y éste para indicar el presente o el futuro.

La partícula "ن- "lam" de negación sólo funciona con el verbo en presente, pero indica siempre un tiempo pasado, por ejemplo:

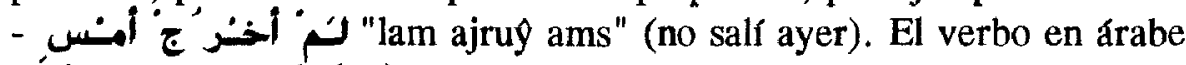
está en presente (salgo).

Al contrario, algunas partículas condicionales rigen verbos en pasado, pero indican el presente o el futuro, por ejemplo:

- "idāà anta akramta al-karīma malaktahu" (Si honras al generoso lo posees). El verbo árabe está en pasado (honraste).

Debemos señalar aquí que estos usos para un nativo resultan totalmente normales y no se para o duda un solo momento para fijarse en ellos por estar acostumbrado a oírlos y verlos.

Pero sí puede causar alguna extrañeza a la hora de hacer un análisis sintáctico o estudiar gramaticalmente estos fenómenos.

La indicación temporal del verbo cambia también en otro caso cuando se trata de los medios de comunicación: prensa, radio, televisión...

El presente en este caso puede indicar pasado o futuro, cuando se emplea en frases que carecen de otros indicadores temporales y lo único que aclara la situación es el contexto y la información anterior que tiene el receptor sobre el asunto:

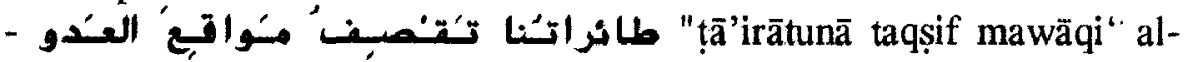
"aduw" (Nuestros aviones bombardean las posiciones enemigas). La frase carece de cualquier indicador temporal, dependiendo de la difusión de la noticia en la radio (Hassan: s.d., 258). El receptor en este caso supone, por estar informado, que el hecho ocurrió ayer o esta mañana.

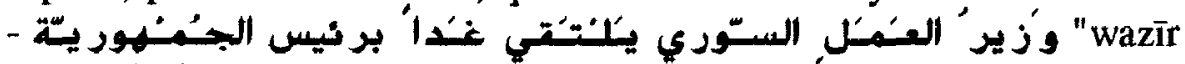
al-'amal al-sūrī yaltaqī gadan bi-ra'îs al-ŷmhūriyya" (el Ministro de Trabajo sirio se encontrará mañana con el presidente de la República). El verbo está en presente (se encuentra) aunque indica futuro.

\section{d) Deíxis, anáfora y discurso:}

La deíxis mostrativa, como hemos visto, señala cosas u objetos en la situación de habla, y la fórica es cuando no se señalan objetos en dicha situación, sino hacia elementos que aparecen antes (anáfora), o 
después (catáfora) que el pronombre en el discurso del habla y que se refieren, en general, a objetos ausentes (López: 1990, 245).

En la deíxis mostrativa la conexión es evidente el pronombre (elemento extralingüístico) y el objeto señalado como entorno pragmático.

Pero la conexión de la déxis fórica es sintagmática e intralingüística, y así el referente de un pronombre de uso fórico es determinado elemento, antecedente o consecuente, que aparece en el contexto lingüístico inmediato (López: 1990, 245).

Sin duda el tipo de relación o conexión que se establece en la déxis forica (entre pronombre y objeto) es reinterpretada a partir de la relación en la déxis mostrativa.

Según J. Calvo, esta deíxis está centrada en el antes y el después del contexto, y que el español cita según proximidad, como muestra el ejemplo siguiente:

- Los griegos combatieron a los persas. Éstos llegaron a invadir su (de los griegos) territorio, pero aquéllos resultaron al fin vencedores (Calvo: 1989, 157).

Lo mismo podemos decir de la lengua árabe, aunque el sistema o el proceso de la referencia puede ser mucho más variado y complejo en comparación con el español. También se cita en árabe por proximidad, aunque podemos encontrar tres tipos distintos de referencias en cuanto al orden, nos referimos al referente del pronombre:

1- Anticipado por dicción y jerarquía:

Esto se produce cuando aparece el referente antes que el pronombre, por ejemplo:

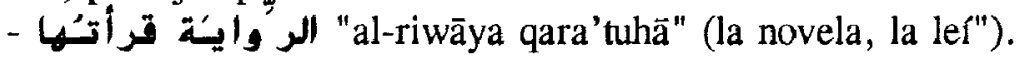

El pronombre sufijo ما que equivale a "la" hace referencia a la novela que está adelantada por dicción "expresamente" y por jerarquía por formar el primer elemento de una frase nominal مسُبْتد "mubtada" (iniciador) que debe ir delante obligatoriamente.

2- Por dicción, pero no por jerarquía:

Se produce cuando se menciona el referente antes que el pronombre, en cambio su orden corresponde a un lugar posterior al pronombre:

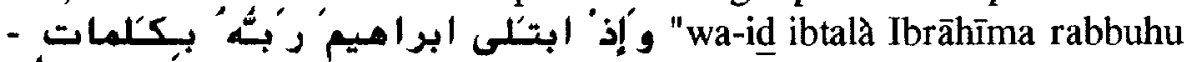
bi-kalimāt" (Y cuando probó Ibrahim, su Señor) (al-Qur'ān: 2-124). 
La '. "hu" (su) hace referencia a Ibrahim que es O.D. y deberfa por su jerarquía estar detrás del sujeto "su Señor".

3- Por jerarquía, pero no por dicción:

Se produce cuando se menciona el pronombre primero y luego el referente. Éste debería estar antes del pronombre por su jerarquía en la frase:

- fa-awỵasa fĩ nafsihi jifa Müsà" (Temió en sus ádéntros Moisés) (al-Qur'ân: 20-67). La • "hi" (su) hace referencia a Moisés que desempeña el papel de sujeto y por jerarquía éste tiene que venir antes que el sintagma preposicional, donde aparece el pronombre.

\section{e) Deíxis en fantasma:}

Con este tipo de déxis se entiende aquel uso deŕctico con el que se apunta a objetos extralingǘsticos que no se encuentran, sin embargo, presentes en la situación del habla, cuando se apunta a los objetos evocándolos (López: 1990, 246).

Como ejemplo de esta deíxis Bühler recuerda una representación china en San Francisco en la cual, para él, todo lo que acontecía en el escenario era reproducido de un modo absolutamente paradigmático en la más simple deíxis en fantasma. Por ejemplo: dos ejércitos (conducido uno por el principio del mal con máscara negra, el otro por el luminoso principio del bien) miman una batalla. En el escenario hay de hecho dos largas mesas a poca distancia; el espacio entre ellas significa un río; una tabla por encima, el puente; un factótum que no toma parte en la representación aparta la tabla; el puente es destruido; un grupo de actores con plumeros de colas de caballo en la mano: la caballería; los plumeros arrojados al suelo: los jinetes están desmontados, etc. (Bühler: 1979, 157).

El autor compara esta representación con la actuación de los niños en sus cuentos y en ambos casos hay quien conduce a otro en fantasma.

Otro ejemplo que puede ser ilustrativo es el del turista que se encuentra en alguna ciudad que desconoce y está buscando alguna oficina en concreto, preguntando por ella a otro que se desenvuelve bien en dicha ciudad. Éste le traza un itinerario que el turista va siguiendo en su imaginación hasta el punto donde se encuentra aquella oficina. Una vez allr en este espacio construido en la imaginación, el hablante 
orienta al turista con un gesto deŕctico que acompaña normalmente a la derxis mostrativa, señalando un espacio imaginario.

\section{Verbos deícticos}

Existen verbos que incluyen en su descripción semántica una referencia al lugar de la enunciación, como por ejemplo el verbo VENIR. Este verbo se utiliza en inglés, francés e italiano, por ejemplo, cuando el desplazamiento se orienta tanto hacia el polo emisor como al receptor (Lozano: 1989, 99).

En cambio en español el verbo venir se usa únicamente cuando el desplazamiento se dirige hacia el emisor. Se dice: Cristina viene a esta escuela, pero Cristina va a la estación. A nivel popular y familiar se utiliza de forma errónea al decir: ¿Vienes al cine conmigo?, en lugar de ¿vas conmigo al cine?

El Diccionario de la Real Academia Española define el verbo venir como: "Caminar una persona o moverse una cosa de allá hacia aca"; "Llegar una persona o cosa a donde está el que habla". Y el Diccionario de uso del español de María Moliner define el mismo verbo como: "Andar o moverse hacia el lugar donde está el que habla".

El árabe coincide con el español en este aspecto, aunque hay varios

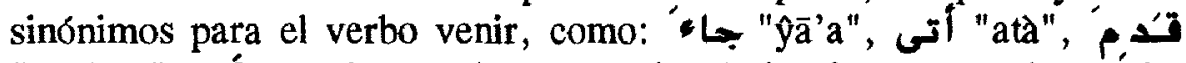
"qadima"... Éste último da lugar a varias derivaciones entre las cuales encontramos قد "qadam" (pie), creemos que la relación gráfica entre venir y pie está muy clara.

El valor dé́ctico del verbo traer se puede apreciar con facilidad, puesto que se utiliza refiriéndose al lugar donde está el emisor. El Diccionario de la R.A.E. lo define asf: "Conducir o trasladar una cosa al lugar en donde se habla o de que se habla". El de María Moliner lo define como: "Transportar una cosa al sitio en que está el que habla".

Existe también un uso no deíctico de este verbo cuando se utiliza en el sentido de llevar, cuando hace referencia a un sitio donde se encuentra otra persona, por ejemplo:

- "Le he traído la radio para escuchar las noticias".

En árabe este concepto se expresa a través de varios verbos que son sinónimos, pero el verbo principal es: "جـلـب "yalaba", en cambio los otros verbos son los mismos que significan "venir", pero aqui hay que 


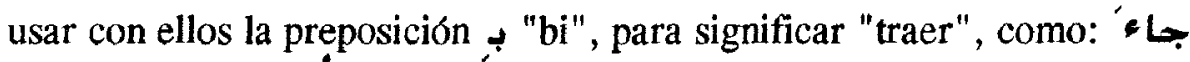
" $\hat{y} \bar{a}$ 'a bi", أتى "atà bi".

\section{CONCLUSIONES}

1- La déxis es la localización y la identificación de las personas, objetos..., de quien se habla por relación al contexto espacio temporal creado y mantenido por el acto de enunciación.

2- La déxis de persona señala al sujeto de la enunciación. Emisor "yo" o al que ve dirigida la enunciación, Receptor "tú". También puede señalar a un elemento necesario como referencia absoluta que es "el". 3- Los pronombres personales en árabe a diferencia de los castellanos tienen un nosotros para el dual masculino o femenino, un tú femenino diferente al masculino y una para el dual de la tercera persona, es decir, ellos dos o ellas dos.

4- El uso del dual en todos los aspectos, tanto en los pronombres como en los verbos es muy reducido y generalmente se utiliza a nivel literario y culto. En el habla popular se utiliza el plural para el dual.

5- Para el plural irracional, tanto masculino como femenino, el árabe utiliza el pronombre de la tercera persona singular femenino "hiya" (ella). Este fenómeno abarca también el verbo, de manera que hablar o indicar el plural irracional siempre se hace desde la perspectiva del femenino singular en tercera persona.

6- Los demostrativos (deixis espacial) que sirven para hacer referencia a la distancia a que se encuentran otros, en árabe admite tres grados: próximo, medio y lejano. Lo mismo ocurre con los demostrativos de lugar, pero el uso se reduce a dos distancias: cercana y lejana.

7- Los def́cticos temporales en árabe tienen un uso complejo a nivel sintáctico. Lo mismo el verbo y sobre todo el presente, que puede indicar presente, pasado o futuro según la partícula que le acompañe.

8- La deíxis en fantasma se refiere a aquel uso dé́ctico con el que se apunta a objetos extralingǘsticos que no se encuentran, sin embargo, presentes en la situación del habla, cuando se apunta a los objetos evocándolos.

9- Los verbos dé́cticos son los que incluyen en su descripción semántica una referencia al lugar de la enunciación, como el verbo 
venir. Este verbo se utiliza en árabe como en lengua española solamente cuando el desplazamiento se dirige hacia el emisor.

10- Podemos afirmar que existen grandes coincidencias entre el árabe y el español en cuanto a la deíxis en general, aunque el árabe se caracteriza por algunos detalles y peculiaridades que son diffcilmente encontrables en otras lenguas, por el factor social y las funciones sociales de la lengua que han influido en su formación, pulición y enriquecimiento que han sido señalados por lingüistas árabes desde hace siglos como Ibn Ŷinn̄i (siglo X).

\section{BIBLIOGRAFÍA}

- Abū Sa'ad, A. (1987): Dalit al-i'rāb wa-l-imlä' ("Guía de gramática y dictado"), Beirut, Dār al-'Ilm li-1-Malāyīn.

- Bühler, K. (1979): Teorla del lenguaje, Madrid, Alianza Universidad. - Calvo, J. (1989): Formalización perceptiva-topologica de la pragmatica liminar, Murcia, Universidad de Murcia.

- Calvo, J., trabajo inédito sobre la deíxis.

- Corriente, F. (1984): Gramática árabe, Madrid, Instituto HispanoÁrabe de Cultura.

- Escandell, M. V. (1993): Introducción a la pragmática, Barcelona, Anthropos.

- Hassān, T. (s.d.): Al-luga al-'arabiyya, ma'nāha wa-mabnäha ("La lengua árabe: su significado y su estructura"), Casablanca, Dār alTaqāfa.

- López, A. (1990): Lingülstica general y aplicada, Valencia, Universidad de Valencia.

- Lozano, J. y otros (1989): Análisis del discurso. Hacia una semiótica de la interacción textual, Madrid, Cátedra.

- Lyons, J. (1980): Semántica, Barcelona, Teide.

- Al-Qur'än (s.d.): Bagdad, Maktaba al-Nahda.

- Reyes, G. (1990): La pragmática linguística, Barcelona, Montesinos.

- Riloba, F. (1986): Gramática arabe-espantola, Madrid, Edi 6.

- Al-Zawzan̄, (s.d.): Šarh al-Mu'allaqãt al-Sab' ("Comentario de los siete poemas al-Mu'allaqāt"), Beirut, Dār al-Fikr. 